\title{
Knowledge and Attitude of Pregnant Women toward Elective Cesarean Section in Saudi Arabia
}

\author{
Afaf Abdul-Jabar Al Sulamy' ${ }^{1}$, Shadia A. Yousuf' ${ }^{2}$, Hala Ahmed Thabet ${ }^{3}$ \\ ${ }^{1}$ Department of Maternity and Child Nursing, Faculty of Nursing, King Abdulaziz University, Jeddah, Saudi Arabia \\ ${ }^{2}$ Department of Primary Health Nursing, Faculty of Nursing, Jeddah, Saudi Arabia \\ ${ }^{3}$ Woman's Health and Midwifery Nursing Department, Faculty of Nursing, Mansoura University, Mansoura, Egypt \\ Email: af-faff@hotmail.com
}

How to cite this paper: Al Sulamy, A.A.-J., Yousuf, S.A. and Thabet, H.A. (2019) Knowledge and Attitude of Pregnant Women toward Elective Cesarean Section in Saudi Arabia. Open Journal of Nursing, 9, 199-208. https://doi.org/10.4236/ojn.2019.92020

Received: January 18, 2019

Accepted: February 25, 2019

Published: February 28, 2019

Copyright ( 2019 by author(s) and Scientific Research Publishing Inc. This work is licensed under the Creative Commons Attribution International License (CC BY 4.0).

http://creativecommons.org/licenses/by/4.0/ (c) (i) Open Access

\begin{abstract}
Background: The rate of deliveries by cesarean section (CS) is increasing worldwide. An elective cesarean section (ECS) is a cesarean section carried with or without a medical reason, in some cases choice by pregnant women. The number of women demanding for delivery by elective cesarean section is increasing in Saudi Arabia. Although CS is the commonest major surgery performed in Obstetrics throughout the world; there are still concerns about the knowledge and attitude of Saudi Pregnant women towards it. Methods: The design of this study was a quantitative, descriptive, and cross-sectional design. The study sample consisted of 206 pregnant women attending antenatal clinic during the third trimester, selected by convenience sampling method from Maternity and Children Hospital in Jeddah City in Saudi Arabia. Structured interview questionnaire was used in this study. Different statistical procedures were used for data analysis including percentages, mean, and mean percentages. Content validity and reliability were done. Results: The majorities $(78.2 \%)$ of the pregnant women have adequate level of knowledge about ECS, $14.6 \%$ of them have moderate knowledge, and only $7.3 \%$ have inadequate knowledge. Also, 137 (66.5\%) of pregnant women have negative attitude toward ECS, while 58 (28.2\%) have positive attitude. Conclusion and recommendations: The study concluded that there was a good level of knowledge among pregnant women about ECS in most of the instrument questions in general; except in some areas such as the bad consequences of CS. On the other hand, the majority of the pregnant women had negative attitude toward ECS. Health care provider such as doctors, nurses and midwives should provide adequate knowledge to the pregnant women about consequence of cesarean section on the mother and child. Various interven-
\end{abstract}


tions are recommended to decline unnecessary cesarean section. These interventions need to contain changes in attitude and correcting misperceptions among pregnant women to cesarean section and normal delivery during the prenatal period.

\section{Keywords}

Knowledge, Attitude, Elective Cesarean Section

\section{Introduction}

Cesarean section is the most common obstetrical operation worldwide [1]. The World Health Organization (2015) specified that $15 \%$ is the rate considered acceptable for delivery by CS in each country since 1985 . However, there is no evidence displaying the benefits of cesarean delivery for women or infant who does not require the procedure [2]. The number of women requesting for delivery by elective cesarean section is increasing global [2] [3] [4]. The rate of the cesarean section also increased in Saudi Arabia, in Jeddah city the rate of CS reached $26.3 \%[5]$.

Elective Cesarean Section is executed in relation to the obstetrical or medical reasons [6] or requested by the pregnant women without any medical reasons [7]. Cesarean section is major surgery and can cause complications to pregnant women when compared to normal vaginal birth [8]. The common complications are hemorrhage, uterus and urinary tract, infection of the wound, and abdominal organ injury [9]. Moreover, the progress of recovery takes longer than vaginal delivery [10]. In addition, CS can cause complications to the newborn such as respiratory distresses, birth trauma and hypoglycemia [11].

Zhao and Chen (2013) stated that the rate of deliveries by ECS is increasing in different parts of the world, due to progression in the medical profession; changing the outlook of the society regarding ECS and perceptions of ECS is the safest method of delivery; pregnant women favored ECS. Studies revealed that pregnant women performed ECS in the absence of any medical indication [7]. The reasoning behind this practice is psychological reasons such as the fear of normal delivery or had previous bad experience with the delivery and the influence of other such as husband, family, physician, and friends [12]. Moreover, the women feel that they have better care with ECS in a hospital [13]. Additionally, some of the husbands, relatives of the pregnant women and pregnant women select an elective cesarean section to deliver a child at a particular date and time in some culture [10].

Furthermore, some of the pregnant women described their positive attitude to CS as less pain than vaginal delivery and safer [14], also, to avoid delivery pain, and worrying about the influence of vaginal delivery on future sex life women prefer ECS [14] [15].

This study on the knowledge and attitude of pregnant women about elective 
cesarean deliveries might help to define strategies for decreasing cesarean delivery rates. This study would also contribute to and improve knowledge to the healthcare providers, such as nurses, midwives, and obstetricians in relation to ECS. It would also assist the healthcare providers to develop educational program material to support women going for ECS. Therefore, the main aim of this study was to assess the knowledge and attitude of the pregnant women regarding elective cesarean section in Maternity and Children Hospital in Jeddah City.

\section{Materials and Methods}

The study adopted a quantitative descriptive cross-sectional design. The target population of this study consisted of the pregnant women who came to the antenatal clinic during the third trimester in Maternity and Children Hospital in Jeddah City. The convenience sampling method was used. The study sample was calculated using the formula (Robert Mason), the calculated sample was 206 pregnant woman, all of the pregnant women responded to the study questionnaire. The study instrument included a structured interview questionnaire. It includes three parts. Part one consists of two sections; Section one concerns data on socio-demographic characteristics of the pregnant women. Section two consisted of obstetric history. Part two consists of six questions related to knowledge about cesarean section with "yes" or "no" answer, the maximum score is (6), and the lowest score is (0) "one point for each". Part three consists of 12 questions related to attitude toward elective cesarean section on a Likert scale (Strongly Disagree $=1$, Disagree $=2$, Neutral $=3$, Agree $=4$, and Strongly Agree $=5$ ), the maximum score is (60), and the lowest score is (12). Some of the questions have negatively worded. Content validity was done by the researcher. Statistical methods that have been used include descriptive statistics, such as mean, standard deviation, and mean percentages.

\section{Ethical Considerations}

The researcher was committed to all ethical considerations required to conduct this study, ethical approval was obtained from King Abdulaziz University, Ministry of Health and Maternity and Children Hospital in Jeddah City. More importantly, informed consent was obtained from all pregnant women to fill up the questionnaire.

\section{Results}

Regarding demographic and personal characteristics of the pregnant women, $128(62.1 \%)$ of pregnant women was 25 to less than 34 years old. Where about 51 (24.8) was 35 or more years old and only 27 (13.1\%) of the pregnant women was less than 25 years old. Also, more than half 119 (57.8\%) have a university degree, $66(32.0 \%)$ of the pregnant women have a secondary school and 16 (7.8\%) of them have a primary school. Additionally, 143 (69.4\%) of the pregnant women are housewives, and $42(20.4 \%)$ of them are employees (Table 1). Regarding the reproductive history of the pregnant women, $94(45.6 \%)$ of the 
pregnant women are have had 2 - 3 times pregnancy, while $56(27.2 \%)$ were pregnant for the first time. Also, 72 (35.0\%) of pregnant women have 2 - 3 deliveries, and $56(27.2 \%)$ do not have any deliveries. Additionally, 134 (65.0\%) of the pregnant women have not experienced abortion, and 51 (24.8\%) of them have a history of abortion for one time. On the other hand, the mode of last delivery for $42.2 \%$ of the study participants was by the normal vaginal method, while $29.6 \%$ of them were by Cesarean section (Table 2).

\subsection{Knowledge of Pregnant Women about Elective Cesarean Section}

The total mean score of pregnant women's knowledge about ECS is 5.04 out of 6 with a mean percentage of $84.0 \%$. The vast majority (98.5\%) of women heard about CS. Also, $90.3 \%$ of them know that Cesarean section needs a blood transfusion in some cases. Moreover, $94.2 \%$ of women knew that CS saves the life of the newborn (Table 3).

\subsection{Attitude of Pregnant Women about Elective Cesarean Section}

The results showed that the higher mean score of attitude items is that "I can define the exact time of my delivery", with a mean score percentage of $66.8 \%$. The lowest one is "I will be more valuable for my husband, if the delivery costs more", with a mean score percentage of $43.6 \%$. The total mean score of pregnant women's attitude about elective cesarean section is 33.23 out of 60 with a mean percentage of $55.38 \%$ (Table 4).

\subsection{Classifications of Pregnant Women's Knowledge and Attitude about Elective Cesarean Section}

Table 5 shows that the majorities $(78.2 \%)$ of the pregnant women have adequate level of knowledge about ECS, $14.6 \%$ of them have moderate knowledge, and only $7.3 \%$ have inadequate knowledge. Also, 137 (66.5\%) of pregnant women have negative attitude toward ECS, while 58 (28.2\%) have positive attitude.

\section{Discussion}

Regarding the results of knowledge of pregnant women about ECS, the study results are nearly consistent with some results of Ashimi et al. (2013), in which it revealed that $93.8 \%$ of the study participants in Nigeria heard about CS [16]. In the current study, participants knowledge regarding blood transfusion was highest than what has been revealed by the study of Ashimi et al. (2013) which revealed that $86.4 \%$ of them were aware that blood may be required for the procedure [16]. On the other hand, the current study result revealed that $82.5 \%$ of the pregnant women knew that vaginal delivery was possible after a cesarean section [16]; this result is consistent with the result obtained by the study of Ashimi et al. (2013) which revealed that $94.4 \%$ of the pregnant women knew that vaginal delivery was possible after a cesarean section [16]. If we have a look at 
Table 1. Sample distribution according to age groups, level of education, and job of study participants $(n=206)$.

\begin{tabular}{ccc}
\hline Variables & Number & Percentage \% \\
\hline Age groups & 27 & 13.1 \\
Below 25 years & 128 & 62.1 \\
25 - 34 years & 51 & 24.8 \\
$\geq 35$ years & Mean $\pm \mathrm{SD}=30.68 \pm 5.42$ & \\
& & 7.8 \\
Level of education & 16 & 32.0 \\
Primary school & 66 & 57.8 \\
Secondary school & 119 & 2.4 \\
University & 5 & 10.2 \\
Others & & 69.4 \\
Job & 21 & 20.4 \\
Student & 143 & \\
Housewife & 42 & \\
Employee & &
\end{tabular}

Table 2. Sample distribution according to gravidity, parity, and mode of last delivery ( $\mathrm{n}=$ 206).

\begin{tabular}{|c|c|c|}
\hline Variables & Number & Percentage \% \\
\hline \multicolumn{3}{|l|}{ Gravidity } \\
\hline Once $^{1}$ & 56 & 27.2 \\
\hline $2-3$ times & 94 & 45.6 \\
\hline$\geq 4$ times & 56 & 27.2 \\
\hline \multicolumn{3}{|l|}{ Parity } \\
\hline Zero & 56 & 27.2 \\
\hline 1 & 44 & 21.4 \\
\hline $2-3$ times & 72 & 35.0 \\
\hline$\geq 4$ times & 34 & 16.5 \\
\hline \multicolumn{3}{|l|}{ Abortion } \\
\hline Zero & 134 & 65.0 \\
\hline 1 time & 51 & 24.8 \\
\hline$>1$ time & 21 & 10.2 \\
\hline \multicolumn{3}{|l|}{ Mode of last delivery } \\
\hline NVD & 87 & 42.2 \\
\hline CS & 61 & 29.6 \\
\hline Instrumental & 2 & 1.0 \\
\hline Didn't give birth before & 56 & 27.2 \\
\hline
\end{tabular}

${ }^{1}$ This is the first pregnancy. 
Table 3. Knowledge of pregnant women about elective cesarean section.

\begin{tabular}{|c|c|c|c|}
\hline Knowledge item & $\begin{array}{c}\text { True answer } \\
\mathrm{N}(\%)\end{array}$ & $\begin{array}{l}\text { False Answer } \\
\text { N (\%) }\end{array}$ & $\begin{array}{l}\text { Total } \\
\mathrm{N}(\%)\end{array}$ \\
\hline Have you heard about CS & $203(98.5)$ & $3(1.5)$ & $20(100.0)$ \\
\hline $\begin{array}{l}\text { Cesarean section need blood } \\
\text { transfusion in some cases }\end{array}$ & $176(90.3)$ & $20(9.7)$ & $20(100.0)$ \\
\hline $\begin{array}{l}\text { Cesarean section requires a } \\
\text { longer stay in hospital after delivery }\end{array}$ & $176(85.4)$ & $30(14.6)$ & $20(100.0)$ \\
\hline $\begin{array}{l}\text { Vaginal delivery is } \\
\text { possible after Cesarean section }\end{array}$ & $170(82.5)$ & $36(17.5)$ & $20(100.0)$ \\
\hline $\begin{array}{l}\text { Dose Cesarean section } \\
\text { save the life of newborn }\end{array}$ & $194(94.2)$ & $12(5.8)$ & $20(100.0)$ \\
\hline $\begin{array}{c}\text { Is there any bad consequences } \\
\text { of Cesarean section }\end{array}$ & $111(53.9)$ & $95(46.1)$ & $20(100.0)$ \\
\hline Mean (\%) \pm SD score of knowledge ${ }^{1}$ & & $5.04(84.0 \%) \pm 0.94$ & \\
\hline
\end{tabular}

${ }^{1}$ Maximum score of knowledge is 6.0 (100.0\%).

Table 4. Attitude of pregnant women about elective cesarean section.

\begin{tabular}{|c|c|c|c|}
\hline Attitude & Mean & $\mathrm{SD}$ & Mean \% \\
\hline $\begin{array}{l}\text { I can define the exact } \\
\text { time of my delivery }\end{array}$ & 3.34 & 0.98 & 66.8 \\
\hline $\begin{array}{l}\text { I will receive more attention } \\
\text { from my family members }\end{array}$ & 3.32 & 0.94 & 66.4 \\
\hline $\begin{array}{l}\text { I will receive better nursing } \\
\text { care during cesarean section }\end{array}$ & 3.15 & 1.00 & 63.0 \\
\hline $\begin{array}{l}\text { Medical care during cesarean } \\
\text { is better than vaginal delivery }\end{array}$ & 3.03 & 0.99 & 60.6 \\
\hline $\begin{array}{l}\text { I had bad experience in } \\
\text { my previous vaginal delivery }\end{array}$ & 2.80 & 0.90 & 56.0 \\
\hline $\begin{array}{l}\text { Cesarean delivery } \\
\text { prevents neonatal death }\end{array}$ & 2.79 & 0.66 & 55.8 \\
\hline $\begin{array}{l}\text { Cesarean is more comfortable } \\
\text { than vaginal delivery }\end{array}$ & 2.77 & 0.95 & 55.4 \\
\hline $\begin{array}{l}\text { I will have caesarean because } \\
\text { of anesthesia during cesarean }\end{array}$ & 2.69 & 0.70 & 53.8 \\
\hline $\begin{array}{l}\text { Those who want only one or } \\
\text { two children are better to do cesarean }\end{array}$ & 2.52 & 0.54 & 50.4 \\
\hline $\begin{array}{l}\text { Children who are born via } \\
\text { cesarean section are smarter }\end{array}$ & 2.39 & 0.77 & 47.8 \\
\hline $\begin{array}{l}\text { I have insurance, I'm not worried } \\
\text { about the cost of cesarean section }\end{array}$ & 2.25 & 0.78 & 45.0 \\
\hline $\begin{array}{l}\text { I will be more valuable for my husband, } \\
\text { if the delivery costs more }\end{array}$ & 2.18 & 0.89 & 43.6 \\
\hline Total & $33.23^{1}$ & 1.59 & $55.38^{2}$ \\
\hline
\end{tabular}

${ }^{1} 34.50$ out of $60.0,{ }^{2}$ Calculated by dividing 33.23 on 60.0 . 
Table 5. Classifications of pregnant women's knowledge and attitude about elective cesarean section.

\begin{tabular}{|c|c|c|}
\hline Variables & Number & Percentage \\
\hline \multicolumn{3}{|l|}{ Level of Knowledge ${ }^{1}$} \\
\hline $\begin{array}{l}\text { Below } 3.6 \text { scores "<60.0\%" } \\
\text { (Inadequate knowledge) }\end{array}$ & 15 & 7.3 \\
\hline $\begin{array}{l}3.6 \text { - } 4.2 \text { scores " } 60.0 \%-70.0 \% " \\
\text { (Moderate knowledge) }\end{array}$ & 30 & 14.6 \\
\hline $\begin{array}{l}\text { More than } 4.2 \text { scores " }>70.0 \% " \\
\quad \text { (Adequate knowledge) }\end{array}$ & 161 & 78.2 \\
\hline \multicolumn{3}{|l|}{ Level of Attitude ${ }^{2}$} \\
\hline$\leq 60.0 \%$ (Negative) & 147 & 71.4 \\
\hline$>60.0 \%$ (Positive) & 59 & 28.6 \\
\hline Total & 206 & 100.0 \\
\hline
\end{tabular}

${ }^{1}$ The maximum score is $6(100.0 \%) .{ }^{2}$ The maximum score is $60(100.0 \%)$.

the total knowledge score in the current study, we could find that $78.2 \%$ of the pregnant women have adequate level of knowledge and $7.3 \%$ have inadequate knowledge; these results are not consistent with the results of Ashimi et al., in which their study revealed that $59.1 \%$ of the pregnant women have adequate knowledge and $40.9 \%$ of them have adequate level [16]. Moreover, the current study results are not consistent with the results of Shahraki-Sanavi et al. (2012) which revealed that the total mean percentage of women's knowledge regarding CS is $68.78 \%$ [17].

The inconsistency between some of the current study results and the results of Ashimi et al. (2013) and the results of Shahraki-Sanavi et al. (2012) could be attributed to the differences in the sample size, and the educational level as well as the experiences of the pregnant women who have been included in this study which is different from what has been included in the study of Ashimi et al., and this what has been proved by the Ashimi et al. since the most of the mothers who has been surveyed were not educated and were unemployed, thus this issue can affect the knowledge. Moreover, the personal characteristics of the women included in this study may be different from what has been included in the study of Ashimi et al. (2013). On the other hand, the current study results are not also consistent with the results of Ghotbi et al. (2014) in Iran which revealed that $6.5 \%$ of the mothers have good knowledge and $55.6 \%$ of them have a poor level. This could be attributed to the nature of the knowledge scale which was used in the current study and the scale which was used in that study, the differences in the classifications of knowledge affect the percentage included in each classification; thus could have differences in the total score and the percentage of pregnant women for each knowledge class.

More importantly, the total level of women's knowledge score in the current study is good. This could be attributed to the percentage of women in this study 
who have a university education, in which more than half of them have a university education. Also, it could be attributed to the fact that there is an information revolution in the Kingdom of Saudi Arabia; including health-related information, in which the available internet sources nowadays are rich of medical information, in addition to the experiences obtained by the mothers from their relatives and/or their friends regarding ECS, all of these factors can play important role in this regard.

Regarding the results of the attitude of pregnant women about ECS, the total mean percentage of pregnant women's attitude about ECS is 55.38\%. Also, $66.5 \%$ of pregnant women in the current study have negative attitude toward ECS selection, while $28.2 \%$ have a positive one. The total mean of attitude in this is nearly consistent with the mean of the attitude of the study of Le (2016) in Vietnam which revealed that mean score of the attitude about ECS was 8.42 out of 14 with mean percentage $60.14 \%$ which was considered as a moderate level. Moreover, the results of this study is consistent with the results of Yamasmit and Chaithongwongwatthana (2012) in Thailand which revealed that most (87.5\%) of the pregnant women preferred vaginal delivery [15]. On the other hand, the current study results are consistent with the results of Shahraki-Sanavi et al. (2012) in Iran which revealed that the majority of women's attitude toward elective CS was intermediate.

The present study results are not consistent with the results of Ghotbi et al. (2014) which revealed that $44.0 \%$ of pregnant women had positive attitude towards vaginal delivery, and most of the pregnant women have negative attitude toward CS. Moreover, the results of Kamal (2013) in Bangladesh revealed that pregnant women have positive attitude toward ECS which is not consistent with the current study results [18]. On the other hand, the current study results are not consistent with the results of Otogara et al. (2018) in Iran which showed that $84.0 \%$ of pregnant women had planned to have a natural delivery, compared to $60.2 \%$ within the present study [19]. The inconsistency between the current study results and the above studies could be attributed to the type, characteristics, and the culture of participants included in the studies. In general, attitude reflects the culture of the individual, and the attitude of the pregnant mothers toward CS might depend on their thoughts and feelings; fear also can play the role in determining the attitude.

If we have a look at the above results regarding the knowledge toward CS, we could find that the majority of knowledge score of the pregnant women is adequate. On the other hand, the score of attitude is negative among the majority, meaning that the knowledge is not a determinant of attitude in the current study, the women who have been included in the current study could have fear from being engaged in surgical operation like CS even if they have good knowledge score, they just are thinking about the procedure as a surgical one, not from their information background. More importantly, the current study results showed that $39.8 \%$ of pregnant women have the intention to give birth by CS. while the others $(60.2 \%)$ have the intention to give birth by normal vaginal deli- 
very, meaning that their attitudes toward CS are not positive.

\section{Conclusion and Recommendations}

The study concluded that there was a good level of knowledge among pregnant women regarding ECS in most of the instrument questions in general; except in some areas such as the bad consequences of CS. On the other hand, the majority of the pregnant women had negative attitude toward ECS. Health care provider such as doctors, nurses and midwives should provide adequate knowledge to pregnant women about the consequence of CS on the mother and the child. Various interventions are recommended to decline unnecessary cesarean section. These interventions need to contain changes in attitude and correcting misperceptions among pregnant women to cesarean section and normal delivery during the prenatal period.

\section{Acknowledgements}

We acknowledge the contribution of the pregnant women in Maternity and Children Hospital in Jeddah who volunteered as respondents in this study. This study would have not been a success if they did not offer their time, patience and genuine responses to this study. Special gratitude goes to King Abdulaziz University, Faculty of Nursing as well as Ministry of Health in Jeddah for providing ethical clearance of our study. We also thank the management staff of Maternity and Children Hospital for granting us permission to conduct this study. Without the support of all the mentioned and those not mentioned here, this study would not have been successful.

\section{Conflicts of Interest}

Submitting author and coauthors of this article do not have any conflict of interest whatsoever.

\section{References}

[1] Varghese, S., Singh, S., Kour, G. and Dhar, T. (2016) Knowledge, Attitude and Preferences of Pregnant Women towards Mode of Delivery in a Tertiary Care Center. International Journal of Research in Medical Sciences, 4, 4394-4398. https://doi.org/10.18203/2320-6012.ijrms20163299

[2] WHO (2015) WHO Statement on Caesarean Section Rates. http://apps.who.int/iris/bitstream/handle/10665/161442/?sequence $=3$

[3] Zhao, Y. and Chen, S. (2013) Psychosocial Factors for Women Requesting Cesarean Section. International Journal of Clinical Medicine, 4, 395-399. https://doi.org/10.4236/ijcm.2013.49071

[4] Olieman, R.M., Siemonsma, F., Bartens, M.A., Garthus-Niegel, S., Scheele, F. and Honig, A. (2017) The Effect of an Elective Cesarean Section on Maternal Request on Peripartum Anxiety and Depression in Women with Childbirth Fear: A Systematic Review. BMC Pregnancy and Childbirth, 17, 195. https://doi.org/10.1186/s12884-017-1371-z 
[5] $\mathrm{MOH}$ (2016) Statistical Yearbook-Statistical Yearbook. https://www.moh.gov.sa/en/Ministry/Statistics/Book/Pages/default.aspx

[6] Smith, D., Stringer, E., Vladutiu, C., Zink, A. and Strauss, R. (2016) Risk of Uterine Rupture among Women Attempting Vaginal Birth after Cesarean with an Unknown Uterine Scar. Obstetric Anesthesia Digest, 36, 82-83. https://doi.org/10.1097/01.aoa.0000482616.33162.2d

[7] Loke, A.Y., Davies, L. and Li, S.-F. (2015) Factors Influencing the Decision That Women Make on Their Mode of Delivery: The Health Belief Model. BMC Health Services Research, 15, 274. https://doi.org/10.1186/s12913-015-0931-Z

[8] Gallagher, F., Bell, L., Waddell, G., Benoît, A. and Côté, N. (2012) Requesting Cesareans without Medical Indications: An Option Being Considered by Young Canadian Women. Birth, 39, 39-47. https://doi.org/10.1111/j.1523-536X.2011.00511.x

[9] Noel, K.R., Harris, M., Wilkins, S. and Bruno, T.S. (2016) Cesarean Section Wound Infections and Neonatal Outcomes [8A]. Obstetrics \& Gynecology, 127, 14 S. https://doi.org/10.1097/01.AOG.0000483303.58649.64

[10] Le, P.T.N. (2016) Factors Influencing Intention of Elective Cesarean Section among Pregnant Women in Quang Ngai Province, Vietnam. Journal of Nursing Science and Health, 38, 137-151.

[11] Mylonas, I. and Friese, K. (2015) Indications for and Risks of Elective Cesarean Section. Deutsches Ärzteblatt International, 112, 489-495.

[12] Zhang, S., Huang, X. and Tan, H. (2013) Prenatal Anxiety and Cesarean Section with Non-Medical Indication. Journal of Central South University, 38, 1070-1074.

[13] Ghotbi, F., Akbari Sene, A., Azargashb, E., Shiva, F., Mohtadi, M., Zadehmodares, S. and Farzaneh, F. (2014) Women's Knowledge and Attitude towards Mode of Delivery and Frequency of Cesarean Section on Mother's Request in Six Public and Private Hospitals in Tehran, Iran, 2012. Journal of Obstetrics and Gynaecology Research, 40, 1257-1266. https://doi.org/10.1111/jog.12335

[14] Shams-Ghahfarokhi, Z. and Khalajabadi-Farahani, F. (2016) Intention for Cesarean Section versus Vaginal Delivery among Pregnant Women in Isfahan: Correlates and Determinants. Journal of Reproduction \& Infertility, 17, 230-239.

[15] Yamasmit, W. and Chaithongwongwatthana, S. (2012) Attitude and Preference of Thai Pregnant Women towards Mode of Delivery. Journal of the Medical Association of Thailand, 95, 619-624.

[16] Ashimi, A., Amole, T. and Aliyu, L. (2013) Knowledge and Attitude of Pregnant Women to Caesarean Section in a Semi-Urban Community in Northwest Nigeria. Journal of the West African College of Surgeons, 3, 46-61.

[17] Shahraki-Sanavi, F., Rakhshani, F., Navidiyan, A. and Ansari-Moghaddam, A. (2012) A Study on Attitude of Pregnant Women with Intention of Elective Cesarean Based on Theory of Planned Behavior. Zahedan Journal of Research in Medical Sciences, 14, 95-97.

[18] Kamal, S.M. (2013) Preference for Institutional Delivery and Caesarean Sections in Bangladesh. Journal of Health, Population, and Nutrition, 31, 96-109. https://doi.org/10.3329/jhpn.v31i1.14754

[19] Otogara, M., Karimi-Shahanjarini, A., Hazavehei, S.M.M., Poorolajal, J., Radnia, N. and Tabib, M.S. (2018) The Effects of Social Support on Pregnant Women's Choice of Delivery Method: Application of an Expanded Theory of Planned Behavior. Crescent Journal of Medical and Biological Sciences, 5, 181-188. 